\title{
To the Question of the Formation of Readiness to Professional Communication in a Foreign Language of Future Engineers in a Digital Educational Environment
}

\author{
Demyanenko, M.A., Leyfa A.V. \\ Amur state University, Blagoveshchensk, Russia
}

Keywords: Professional Education, Professional Foreign Language Communication, Readiness for Foreign Language Communication, Digital Educational Environment

Abstract: This article is devoted to the problem of formation of readiness for professional foreign language communication with future engineers in the conditions of the digital educational environment of the University. A brief description of the concept of "digital educational environment” is given.

\section{Introduction}

Modern socio-economic conditions, labor market requirements and the introduction of elements of informatization, computerization and digitalization put forward new requirements for the training of engineers, it is also necessary to take into account the requirements of the employer when including the disciplines of professional and foreign-language orientation in the training of engineers.

The problem of formation of readiness of future engineers to foreign language communication is relevant, as foreign language training is part of the training of engineers in the framework of vocational education. Professional training of engineers is a process of mastering general cultural and professional competencies that allow to perform professional duties in the field of engineering. Professional competence of engineers provides: the effectiveness of professional activity of engineers in enterprises, the successful resolution of their assignments that meet functional responsibilities, their interaction with the working environment and provides the basis for professional self-affirmation and self-improvement of their personality.

New requirements for engineering education on the basis of competence-based approach, suggest the orientation of the educational process on the formation of general cultural, professional, general professional competences laid down in the Federal state educational standards (GEF), and are the key to the successful professional activity of the engineer. Effective professional activity of an engineer largely depends on the mastery of his communicative competence, and also provides the opportunity to communicate with other people, exchange information, develop strategies for interaction in a professional team, interaction in a team of specialists, including foreign ones. 


\section{Materials and Discussion}

The analysis of scientific and pedagogical literature devoted to the problems of vocational education (S.Y. Batyshev, P.F. Kubrushko, V.S. Lednev, A.V. Morozov, etc.) leads to the conclusion that the system of vocational education has certain characteristics, since it is aimed at interaction with the labor market. There is no doubt that it is important and necessary to train personnel with knowledge, abilities and skills not only in the field of oral and written technical translation using digital resources, but also the experience of intercultural communication of a professional orientation. Potential employers have similar requirements for future engineers. All these changes increase the demand for engineers capable of carrying out engineering activities in modern realities, taking into account the conditions determined by the digital educational environment.

Currently, a number of initiatives aimed at creating the necessary conditions for the development of the digital economy are being implemented in Russia, and the "Strategy for the development of the information society in the Russian Federation for 2017-2030" is also of paramount importance [8]. The Decree of the President of the Russian Federation dated 07.05.2018 "On national goals and strategic objectives of the Russian Federation for the period up to 2024" stipulates that one of the priorities in the field of education is "the creation of a modern and safe digital educational environment that ensures high quality and availability of education of all types and levels" [7].

A.V. Morozov understands the digital educational environment as a set of digital educational resources, tools and technologies that provide the educational process in the conditions of digitalization [3]. This definition is based on the provisions of the GEF and current Russian legislation in the field of education.

The digital educational environment should create conditions and contribute to the formation of the competencies of a specialist of the XXI century, namely, according to the provisions of the GEF VO (GEF 3+) for various areas of undergraduate training, important universal competencies are "able to manage their time, build and implement a trajectory of self-development based on the principles of education throughout life" (UK-2), as well as General professional competence "the ability to solve standard problems of professional activity on the basis of information and bibliographic culture with the use of information and communication technologies and taking into account the basic requirements of information security" (OPK-2) and "the ability to use modern information technology and software, including domestic production, in solving problems of professional activity" (OPK-3). For the formation of universal competences of students in an educational institution should be formed socio-cultural environment integrated with the information environment [6].

The issue of creation and development of information educational environment of an educational organization (IOS) is considered in a number of state normative documents, including the Federal law "On education in the Russian Federation", "The Concept of modernization of Russian education until 2020", digital educational environment (DSP) - in the priority project "Modern digital educational environment in the Russian Federation" [4].

In order to determine the essential characteristics of the concept of DSP, which is a systemorganized set of means of data transmission, information resources, protocols of interaction, hardware, software and organizational and methodological support, focused on meeting the educational needs of students [2], it is necessary to consider the components forming it. According to V.G. Manyakhina [1], the DSP consists of the following components: 1) educational module, which contains teaching materials and reference materials; 2) the module of planning, organization and direct management of the educational process (administrative module); 3) the module of communication, which is designed to support communication between students and the teacher; 4) 
the module of operational control of the learning process; 5) the module of management of a set of resources and technical support [2].

\section{Results}

The electronic information and educational environment is understood as a set of information and telecommunication technologies, appropriate technological means, electronic information and educational resources necessary and sufficient for the organization of indirect (at a distance) interaction of students with pedagogical, educational and auxiliary, administrative and economic personnel, as well as among themselves [5]. In our opinion, the digital educational environment of the University is understood as a digital information and educational space, a system-organized set of information, technical and educational-methodical support, presented in digital form and includes digital information resources, digital educational resources, a set of digital information and telecommunication technologies, appropriate digital technology tools and ensuring the development of educational programs by students in full regardless of the location of students.

Thus, the structure of the digital educational environment of the University can be represented in the form of the following components: the official website of the University, electronic personal offices of students and teachers, electronic library systems, corporate mail of the University, distance learning system "Moodle", automated information system of University management on the basis of "1C:Enterprise", the official community of the University in social networks (Instagram, VK, Twitter, Youtube, etc.) (Figure 1).

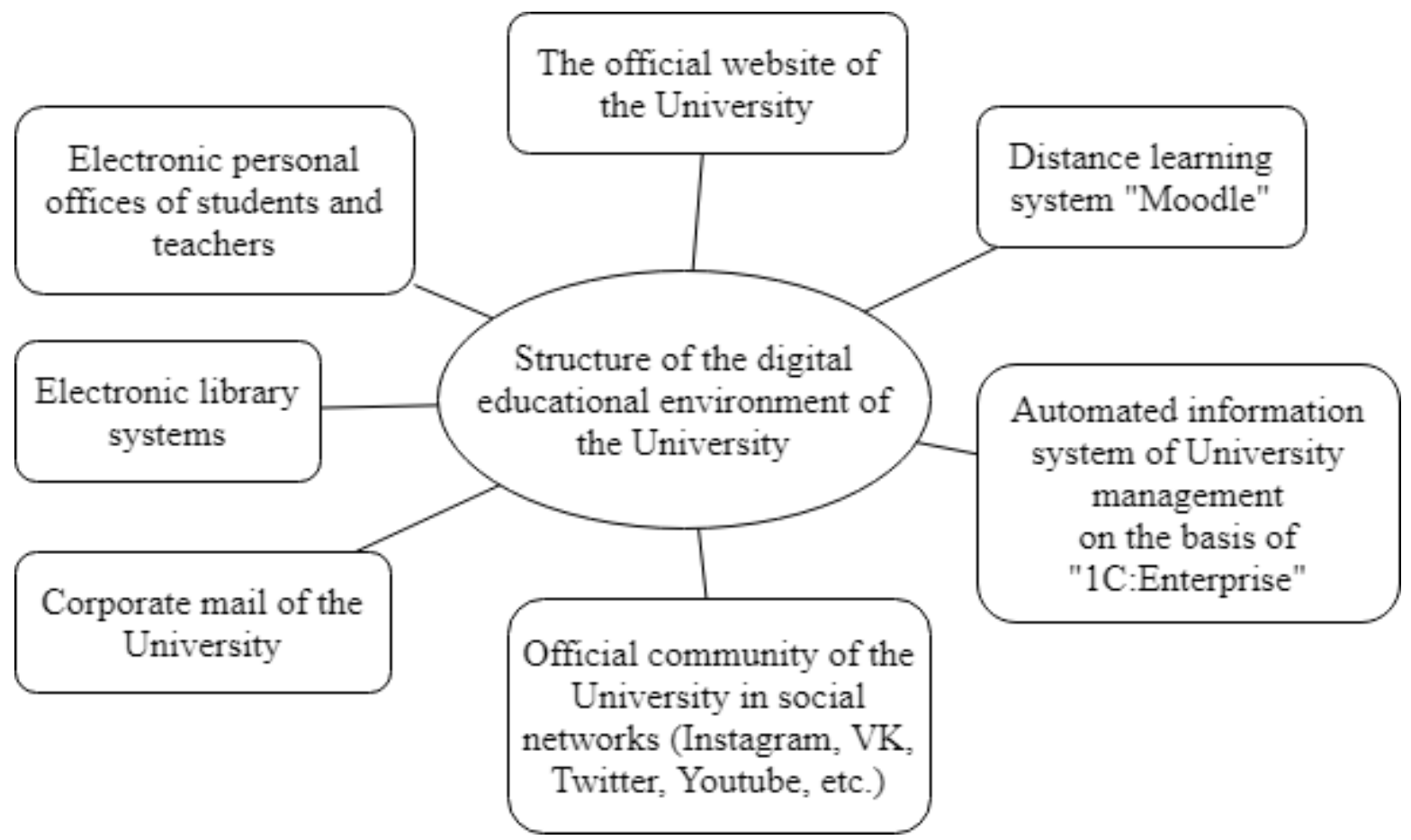

Figure 1. The Structure of the Digital Educational Environment of the University

The official website of the University provides information on the training of future engineers in the form of the following documents: educational program, curriculum, annotations to the working programs, work programs, schedule, practice, guidelines for the study of disciplines, etc.

Electronic personal offices of students and teachers are necessary for the formation, maintenance, storage, support and accounting of personal profiles of competencies, students and teachers, as well 
as for the construction of personal educational trajectories of their development, providing the opportunity to choose students and teachers, taking into account their interests, abilities and inclinations, for the diagnosis of personal abilities of students and teachers, taking into account the digital educational environment.

Electronic library systems are a mandatory element of library and information support of students, which is a database containing publications of educational, methodical and scientific literature used in the educational process. Electronic library systems allow effective use and development of various educational technologies, including distance learning, e-learning in the implementation of educational programs.

Corporate mail of the University is the main means of exchange of information and documents, which is used for document circulation within and between organizations. Corporate mail in a higher education institution is a high efficiency, security, the ability to use corporate standards and a common address book, common rules for sorting and configuring mail, the ability to organize group alerts, meetings, etc., the ability to receive mail on mobile devices, quickly receive and configure the user's mail at another workplace.

The distance learning system "Moodle" is focused on collaboration between students and teachers. The system provides a lot of tools for training engineers: forums, workshops, glossaries, blogs, wikis. At the same time, training can be carried out both asynchronously, when each student studies the material at his own pace, and in real time, organizing online lectures and seminars. The system supports exchange of files of any formats - both between the teacher and the student, and between students. The distance learning system "Moodle" is also used for the network system of advanced training, professional retraining, continuous professional development of teachers, in order to ensure their readiness to implement modern models of the educational process in a digital educational environment.

Atomized information management system of the University on the basis of "1C:Enterprise" contributes to the improvement of document management in the educational organization. This software product allows you to: manage the student body, plan the educational process, calculate the workload of teachers, monitor the educational process, etc., which is aimed at improving the efficiency of the educational institution and the automation of the educational process of the University in a digital educational environment.

Official University communities in social networks (Instagram, VK, Twitter, Youtube, etc.) are necessary to work with both external and internal target audience of the University and has a synergetic effect in relation to all other media communication areas. Social networks are necessary as a tool to motivate students to learn foreign languages and, in General, to train engineers at the University in a digital educational environment.

\section{Conclusions}

Thus, the priority task of universities is the training of future engineers who are able to: competently work with digital content; carry out competent professional foreign language communication; improve the level of their language training. Implementation of these tasks is possible with the effective functioning of the digital educational environment of the University. The introduction of new digital resources in the educational process of the University and the digitalization of education, in General, contribute to the efficiency of the educational process. 


\section{References}

[1] Manyakhina V. G. Organization of out-of-class independent work of future teachers of Informatics in the conditions of application of network distance educational technologies: Diss...kand.PED.Sciences: 13.00.02. / Manyakhina Valentina Gennadievna. - M., 2009. - 181 p.

[2] Modular learning: theoretical issues, experience and prospects / ed. by T. I. Chumovoy. - M., 1994. $134 \mathrm{p}$.

[3] Morozov A.V. Professional training of education system managers using modern digital technologies // People and education. - 2018. - № 4 (57). - P. 105-110.

[4] Passport of the priority project "Modern digital educational environment in the Russian Federation", approved by the Presidium of the Council under the President of the Russian Federation for strategic development and priority projects (Protocol No. 9 of October 25, 2016) // [Electronic resource]

URL: http://static.government.ru/media/files/8SiLmMBgjAN89vZbUUtmuF5lZYfTvOAG.pdf

[5] Plutenko A. D., Leif A. V., Eremin V. V., T. V. Halicka Multilevel training of engineering personnel in the context of continuous education // Vestnik of Tomsk state University. - 2019. - № 439. - P. 178-184.

[6] Plutenko A.D., leifa A.V., Kozyr A.V., Khaletskaya T. V. Professional training of engineers for high-tech enterprises // Pedagogy. - 2018. - № 3. - P. 86-91.

[7] Regulations on the electronic information and educational environment in the Amur state University from 01.09.2017 g. № 248-OD // [Electronic resource] URL: https://cabinet.amursu.ru//uploads/sveden/_Name_Date/514/_Polozhenie_PUD_SMK_1052017_Ob_elektronnoy_informatsionno-obrazovatelnoy_srede_01.09.2017.pdf

[8] Order of the Ministry of education and science of the Russian Federation of 19 September 2017 N 926 "On approval of the Federal state educational standard of higher education in the field of training 09.03.02 Information systems and technologies (bachelor level)"

[9] The decree of the President of the Russian Federation "On the national goals and strategic objectives development of the Russian Federation for the period up to 2024" from 07.05.2018 No. 204 // [Electronic resource] URL: http://kremlin/ru/acts/bank/43027

[10] The decree of the President of the Russian Federation of may 9, 2017 No. 203 “On the Strategy of information society development in the Russian Federation for the years 20172030”https://www.garant.ru/products/ipo/prime/doc/71570570/ 